\title{
Entomopathogenic nematodes and fungi to control Hyalesthes obsoletus (Hemiptera: Auchenorrhyncha: Cixiidae)
}

\author{
Abdelhameed Moussa • Michael Maixner • Dietrich Stephan - Giacomo Santoiemma • \\ Alessandro Passera • Nicola Mori · Fabio Quaglino
}

Received: 20 August 2020/ Accepted: 28 December 2020/Published online: 26 January 2021

(C) The Author(s) 2021

\begin{abstract}
Hyalesthes obsoletus Signoret (Hemiptera: Auchenorrhyncha: Cixiidae) is a univoltine, polyphagous planthopper that completes its life cycle, including the subterranean nymph cryptic stage, on herbaceous weeds. In vineyards, it can transmit 'Candidatus Phytoplasma solani', an obligate parasitic bacterium associated with bois noir $(\mathrm{BN})$ disease of grapevine, from its host plants to grapevine when occasionally feeding on the latter. The main disease management strategies are based on vector(s) control.
\end{abstract}

Handling Editor: Ralf Ehlers.

Supplementary Information The online version contains supplementary material available at https://doi.org/10.1007/ s10526-020-10076-1.

A. Moussa · A. Passera · F. Quaglino

Department of Agricultural and Environmental Sciences Production, Landscape, Agroenergy (DiSAA), University of Milan, Milan, Italy

A. Moussa

Pests and Plant Protection Department, Agricultural and Biological Research Division, National Research Centre, Dokki, Giza, Egypt

M. Maixner

Julius Kühn-Institute (JKI), Institute for Plant Protection

in Fruit Crops and Viticulture, Siebeldingen, Germany

D. Stephan

Julius Kühn-Institute (JKI), Institute for Biological

Control, Darmstadt, Germany
Insecticide treatments on grapevine canopy are completely inefficient on $\mathrm{H}$. obsoletus, due to its life cycle. Consequently, control of this planthopper focuses on the nymphs living on the roots of their host plants. Such practices, based on herbicide application and/or weed management, can reduce vector density in the vineyard but can impact the environment or may not be applicable, highlighting the necessity for alternative strategies. In this study, the efficacy of entomopathogenic nematodes (EPNs; Steinernema carpocapsae, S. feltiae, Heterorhabditis bacteriophora) and fungi (EPFs; Beauveria bassiana, Metarhizium anisopliae, Isaria fumosorosea, Lecanicillium muscarium) against $H$. obsoletus nymphs (EPNs) and adults (EPNs and EPFs) was

\footnotetext{
G. Santoiemma

Department of Agronomy, Food, Natural resources, Animals and Environment (DAFNAE), University of Padova, Padova, Italy

N. Mori $(\square)$

Department of Biotechnology, University of Verona, Verona, Italy e-mail: nicola.mori@univr.it
} 
assessed under laboratory and greenhouse conditions. The majority of examined EPNs and EPFs were able to kill $H$. obsoletus exhibiting a range of effectiveness. $S$. carpocapsae (among EPNs) and I. fumosorosea (among EPFs) were found to be the most effective biocontrol agents in all trials carried out. Advantages and limitations of such promising biocontrol agents were discussed. Ecological competency and conditions that can impede or enhance the EPNs and EPFs performance should be investigated to optimize their performance under field conditions.

Keywords Planthoppers - Grapevine - Bois noir · Sustainability $\cdot$ Entomopathogens

\section{Introduction}

Hyalesthes obsoletus Signoret (Hemiptera: Auchenorrhyncha: Cixiidae) is a polyphagous planthopper able to transmit 'Candidatus Phytoplasma solani' (CaPsol) to plants (Quaglino et al. 2013), including Vitis vinifera L. (Maixner 1994). CaPsol, a plant obligate parasitic bacterium, is associated with bois noir (BN), a disease belonging to the complex of grapevine yellows which had high economic impact on viticulture in Europe in the last decades (Angelini et al. 2018). Although alternative insect vectors of CaPsol to grapevine were recently reported (Cvrković et al. 2014; Quaglino et al. 2019), BN epidemiology is principally determined by the life cycle of its main vector H. obsoletus (Mori et al. 2013).

$H$. obsoletus is a palaearctic, univoltine species that, in Europe, completes its life cycle mainly on bindweed (Convolvulus arvensis L.) and nettle (Urtica dioica L.) (Langer and Maixner 2004) but also on other host plants (Kosovac et al. 2019; Moussa et al. 2019). In summertime, females produce eggs on the root collar of host plants and after egg hatching the nymphs migrate into the soil to the roots from which they can acquire CaPsol. After a latency period, $H$. obsoletus becomes able to transmit CaPsol to plants for the duration of its life. Overwintering occurs as second-third instar nymphs in the soil. Fourth and fifth instar nymphs migrate to the soil surface in early spring. Adults emerge from end of May till end of June and they fly from beginning of July to end of August, based on climate, host plant, and region (Cargnus et al.
2012; Maixner and Johannesen 2014; Alma et al. 2015). During their flights, $H$. obsoletus adults can occasionally feed on grapevine and, if infected, transmit CaPsol. However, due to their limited feeding activity on grapevine and the short lifespan of the adult stage, they cannot transmit $\mathrm{CaPsol}$ from vine to vine. Grapevine is therefore a dead-end host for the pathogen (Bressan et al. 2007).

Since no effective control measures directly targeting phytoplasmas are available, the main strategies to manage the spreading of phytoplasma-associated diseases are based on preventive measures, including the control of vectors before their emergence from the ground (Bianco et al. 2019). Due to its cryptic life cycle and polyphagous feeding habit, insecticide treatments on grapevine canopy are completely inefficient against $H$. obsoletus. Thus, strategies for its control focus on depriving the nymphs of their feeding substrate, the host plant roots. Before adult emergence, bindweed and nettle can be suppressed by planting of ground covering rosette plants, repeated mowing or weeding (Maixner and Mori 2013; Mori et al. 2014a). Since $H$. obsoletus presence depends on the distribution of its natural plant hosts both within and outside the vineyards, such strategies are limited by restrictions on the use of herbicides in uncultivated areas, as well as mechanical weeding on ditches and embankments because of soil landslide. In Israel, H. obsoletus populations within vineyards are successfully limited by a push and pull strategy using chaste tree (Vitex agnus-castus L.) (Sharon et al. 2015), but such a strategy cannot be employed in Europe where this plant hosts both $H$. obsoletus and CaPsol (Moussa et al. 2019).

Considering these limitations, a promising approach to control the vector populations could be based on the utilization of biocontrol agents such as entomopathogenic nematodes (EPNs) and fungi (EPFs). In particular, several Steinernema and Heterorhabditis EPNs have been reported as effective biocontrol agents against a broad range of insects with a cryptic life cycle like H. obsoletus (Grewal et al. 2005; Lacey and Georgis 2012; Guerrero and Pardey 2019). EPNs efficacy depends on their survival for a long time without their host targets in the soil, and their ability to find the hosts by ambush (i.e., Steinernema carpocapsae) or cruising (i.e., Heterorhabditis bacteriophora) strategy (Kaya et al. 1993; Grewal et al. 1994). Concerning EPFs, they are 
reported as important antagonists of soil-dwelling insect pests adapted to live in agricultural soils, such as the grapevine phylloxera in vineyards (Kirchmair et al. 2004). Interestingly, the EPF Metharizium anisopliae showed a great efficacy against $H$. obsoletus adults under laboratory conditions (Langer et al. 2005). In this study, the efficacy of different EPNs and EPFs against $H$. obsoletus nymphs and adults under laboratory and greenhouse conditions were assessed to develop effective and innovative approaches to control the main vector of CaPsol.

\section{Materials and methods}

\section{Hyalesthes obsoletus collection}

Nymphs of $H$. obsoletus were collected on two dates immediately before the different experiments. The collection for laboratory bioassay was done in the middle of May 2019. Nymphs were obtained from pots of stinging nettle plants at the rearing facility in Julius Kühn-Institute (JKI) in Siebeldingen, Germany. Collection for the greenhouse trials was performed in late May 2019 from roots of nettle plants growing at the borders of a highly $\mathrm{BN}$-affected vineyard in Mosel area $\left(49.9198^{\circ} \mathrm{N}, 7.0627^{\circ} \mathrm{E}\right)$, Germany. Nymphs were placed in falcon tubes filled with the same soil in which they were collected and sent to the laboratory for trials. Nymphs identity was confirmed based on the taxonomic key by Stöckmann et al. (2013).

Adults of $H$. obsoletus were collected from bindweed and stinging nettle plants using a sweep net and mouth aspirator from mid-June till the end of July 2019, based on the trial requirements, in the vicinity of highly BN-affected vineyards in Mosel area $\left(49.9198^{\circ} \mathrm{N}, 7.0627^{\circ} \mathrm{E}\right.$, and $\left.49.1928^{\circ} \mathrm{N}, 8.0830^{\circ} \mathrm{E}\right)$, Germany. Collected adults were placed in collapsible insect mesh cages with shoots of nettle plants as food source, transferred to the laboratory, and identified by taxonomic key (Bertin et al. 2010). H. obsoletus adults were subject to immediate use in bioassays and greenhouse efficacy trials.

\section{Entomopathogenic nematodes}

Three EPNs were applied in both bioassays and greenhouse trials against $H$. obsoletus nymphs and adults. In detail, the utilized EPNs (Steinernema carpocapsae, S. feltiae, Heterorhabditis bacteriophora, and a combination (1:1) of $S$. feltiae and $H$. bacteriophora) were purchased from E-nema ${ }^{\circledR} \mathrm{Com}$ pany (Schwentinental, Germany) (Table 1) and maintained at $4{ }^{\circ} \mathrm{C}$. Immediately before using, each EPN (supplied in powder) was suspended in tap water and tested for its viability by counting the infective juveniles (IJs) under stereomicroscope. IJs without a response to stimulators were considered dead (Lacey 1997). All EPNs showed a viability higher than $95 \%$. Before the application, each EPN was serially diluted in tap water to reach the required concentration for bioassay (200 $\mathrm{IJ} \mathrm{ml}^{-1}$ ) and greenhouse trials (400 IJs ml ${ }^{-1}$ ) (Guerrero and Pardey 2019).

\section{Entomopathogenic fungi}

Three distinct EPF isolates of Beauveria bassiana, Metarhizium anisopliae, and Isaria fumosoroseus (provided by Dr. Dietrich Stephan - Institute for Biological Control, JKI, Darmstadt, Germany), were applied in preliminary screening against $H$. obsoletus adults. In addition to these isolates, one commercial isolate of M. anisopliae and one of Lecanicillium muscarium were purchased from Koppert Biological Systems Company (Verona, Italy) and applied in greenhouse trials against $H$. obsoletus adults (Table 1 ). EPFs were cultivated in Petri dishes on malt extract peptone agar (30 $\mathrm{g}$ of malt extract, $3 \mathrm{~g}$ of peptone, $15 \mathrm{~g}$ of agar in 11 of distilled water) previously autoclaved at $121{ }^{\circ} \mathrm{C}$ for $10 \mathrm{~min}$. After inoculation, EPFs were grown for five days at room temperature $\left(22{ }^{\circ} \mathrm{C}\right)$ and for six days at $4{ }^{\circ} \mathrm{C}$. For each EPF isolate, fungal conidia were recovered from the mycelium, suspended in distilled water and counted (three times per isolate) at $400 \times$ magnification through a haemocytometer. For each EPF isolate, stock solutions of conidial suspension were prepared at the concentrations of $10^{6}, 10^{8}$ and $10^{10}$ conidia $\mathrm{ml}^{-1}$ and stored at $4{ }^{\circ} \mathrm{C}$ until use.

Entomopathogenic nematodes: laboratory bioassays

Bioassay to evaluate the efficacy of EPNs against $H$. obsoletus nymphs was conducted in 12-well cell culture plates with lids. According to the protocols of Kaya and Stock (1997) and Glazer and Lewis (2000), in each well, filled with $1 \mathrm{~g}$ of autoclaved sand, $1 \mathrm{ml}$ of 
Table 1 Entomopathogenic nematodes (EPNs) and fungi (EPFs) used against Hyalesthes obsoletus adults and nymphs

\begin{tabular}{|c|c|c|c|c|}
\hline Agent & Scientific name & Strain acronym & Source & H. obsoletus target stage \\
\hline \multirow[t]{4}{*}{ EPNs } & Steinernema carpocapsae & $\mathrm{Sc}$ & E-nema ${ }^{\circledR}$ & Nymphs and adults \\
\hline & Heterorhabditis bacteriophora & $\mathrm{Hb}$ & & \\
\hline & Steinernema feltiae & Sf & & \\
\hline & H. bacteriophora \& S. feltiae & $\mathrm{Hb}+\mathrm{Sf}$ & & \\
\hline \multirow[t]{11}{*}{ EPFs } & Beauveria bassiana & JKI-BI-1124 & Julius Kühn-Institut & Adults \\
\hline & & JKI-BI-1125 & & \\
\hline & & JKI-BI-1126 & & \\
\hline & Metarhizium anisopliae & JKI-BI-1428 & & \\
\hline & & JKI-BI-1429 & & \\
\hline & & JKI-BI-1430 & & \\
\hline & Isaria fumosorosea & JKI-BI-1497 & & \\
\hline & & JKI-BI-1499 & & \\
\hline & & JKI-BI-1500 & & \\
\hline & Metarhizium anisopliae & 1111 & Koppert biological systems company & \\
\hline & Lecanicillium muscarium & 2222 & Company & \\
\hline
\end{tabular}

EPN suspension (200 $\mathrm{IJs} \mathrm{ml}^{-1}$ ) was applied and one nymph was placed. Control plates were treated with distilled water before placing the nymphs. Bioassay to evaluate the efficacy of EPNs against $H$. obsoletus adults was conducted in plastic Petri dishes $(9 \mathrm{~cm}$ diameter) padded with filter paper. Following Glazer and Lewis (2000) procedures, in each dish, fresh shoots of stinging nettle $(5 \mathrm{~cm})$ were placed as a food source together with 12 adults of $H$. obsoletus, and $1 \mathrm{ml}$ of EPN suspension (200 $\mathrm{IJs} \mathrm{ml}^{-1}$ ) was applied using a hand-held sprayer. Control dishes were sprayed with distilled water before placing the adults. The edges of Petri dishes were dried with tissue paper to prevent the adults sticking to water droplets. Three replicates of each plate (nymphs)/Petri dish (adults) were made per EPN as well as the control. All plates/ dishes were placed in a controlled chamber $\left(25^{\circ} \mathrm{C}\right.$, $72 \%$ RH, L:D 16:8) for six days. Mortality readings were taken daily for six consecutive days. To confirm that insect mortality was caused by the activity of the EPNs, the presence of EPN was evaluated by dissecting nymphs and adult insect bodies under a $40 \times$ magnifying stereomicroscope. This was done after rinsing single dead nymphs and adults in a conical flask filled with $20 \mathrm{ml}$ of distilled water, for removing nematodes from their surface. Nymphs and adults were then placed on a moist filter paper padded plastic
Petri dish and maintained at $25^{\circ} \mathrm{C}$ for three days according to Glazer and Lewis (2000).

Entomopathogenic nematodes: greenhouse trials

To evaluate the efficacy of EPNs against $H$. obsoletus nymphs and adults, greenhouse trials were conducted on potted stinging nettle (Urtica dioca L.) and faba bean (Vicia faba L.) plants, respectively. The nettle plants (diameter about $0.1 \mathrm{~m}$ and height approximately $0.4 \mathrm{~m}$ ) were grown in 3.0 l pots, while the bean plants (diameter about $0.1 \mathrm{~m}$ and height approximately $0.25 \mathrm{~m}$ ) in 1.01 pots and placed in transparent plastic ventilated cages. All plants were in good vegetative condition and did not show symptoms of biotic and abiotic stresses. In each pot with nettle, $5 \mathrm{ml}$ of EPN suspension (400 IJs ml ${ }^{-1}$ ) was applied to the soil using a hand-held sprayer, and a total of 20 nymphs were placed after treatment. The control potted plants were treated with $5 \mathrm{ml}$ of distilled water before placing the nymphs. On each caged bean plant, $10 \mathrm{ml}$ of EPN suspension (400 $\mathrm{IJs} \mathrm{ml}^{-1}$, with $0.02 \%$ Tween 80 ) was applied using a hand-held sprayer, and 15 H. obsoletus adults were released. The control caged plants were treated with $10 \mathrm{ml}$ of distilled water with $0.02 \%$ Tween 80 before releasing insect adults. Three replicates, arranged in randomized blocks, were 
made per EPN as well as the control. Potted plants were kept in a controlled chamber $\left(25^{\circ} \mathrm{C}, 72 \% \mathrm{RH}\right.$, L:D 16:8). Mortality was recorded six days after treatment. As described above for the bioassay, mortality due to nematodes infection was confirmed by dissecting the dead nymph and adult insect bodies under a $40 \times$ magnifying stereomicroscope.

Entomopathogenic fungi: laboratory bioassays

Initially, the nine EPF isolates provided by the Institute for Biological Control JKI (Table 1) were screened for their entomopathogenic activity against H. obsoletus adults in plastic Petri dishes $(8.5 \mathrm{~cm}$ diameter), filled to a depth of $5 \mathrm{~mm}$ with a mixture of plaster of Paris and charcoal (10:1) and moistened with distilled water (Green 1964; Langer et al. 2005). In each Petri dish, fresh bindweed (Convolvulus arvensis L.) shoots $(5 \mathrm{~cm})$ were placed as a food source, $1 \mathrm{ml}$ of EPF conidia suspension $\left(10^{8}\right.$ conidia $\mathrm{ml}^{-1}$ ) was applied using a hand-held sprayer, and 12 adults were released. The control dishes were treated with distilled water before the release of insects. Three replicates were conducted per EPF isolate as well as the control. Petri dishes were kept in a controlled chamber $\left(25{ }^{\circ} \mathrm{C}, 72 \%\right.$ RH, L:D 16:8). Mortality readings were taken after six days. Single dead insects from each EPF isolate were placed in malt extract peptone agar plates kept for three days at room temperature $\left(22{ }^{\circ} \mathrm{C}\right)$ and for five days at $4{ }^{\circ} \mathrm{C}$. Mortality due to EPF infection was confirmed through the observation of EPF mycelium growth on the insect body. Subsequently, EPF isolates, found active against $H$. obsoletus in the initial screening test, were employed in a bioassay applying conidial suspension at different concentrations $\left(10^{6}, 10^{8}, 10^{10}{\text { conidia } \mathrm{ml}^{-}}^{-}\right.$ $\left.{ }^{1}\right)$. The bioassays were conducted in plastic Petri dishes as described above for the initial screening test. Three replicates were conducted per concentration per EPF isolate as well as the control. Petri dishes were kept in controlled chamber $\left(25^{\circ} \mathrm{C}, 72 \% \mathrm{RH}, \mathrm{L}: \mathrm{D}\right.$ 16:8) for six days. Mortality readings were taken daily for six consecutive days. Single dead insects from each bioassay were placed in malt extract peptone agar plates and checked to confirm EPF-related mortality as described above.
Entomopathogenic fungi: greenhouse trials

Greenhouse trials were conducted on potted stinging nettle plants, placed singly in transparent plastic ventilated cages, to evaluate the efficacy against $H$. obsoletus adults of the previously selected JKI EPF isolates along with two commercial EPFs (M. anisopliae and L. muscarium). On each caged plant, $1 \mathrm{ml}$ of EPF suspension $\left(10^{8}\right.$ conidia $\left.\mathrm{ml}^{-1}\right)$ was applied on the potted plants using a hand-held sprayer, and $15 \mathrm{H}$. obsoletus adults were released. The control caged plants were treated with $1 \mathrm{ml}$ of distilled water before the release of insects. Three replicates were made per EPF as well as the control. Caged potted plants were kept in a controlled chamber $\left(25^{\circ} \mathrm{C}, 72 \% \mathrm{RH}, \mathrm{L}: \mathrm{D}\right.$ 16:8) for six days. Mortality readings were taken after six days. EPF-related mortality was confirmed by observing the EPFs mycelium growth directly on insect bodies on stinging nettle or placing single dead insects in malt extract peptone agar plates as described above.

\section{Statistical analysis}

In the bioassays, the median lethal time $\left(\mathrm{LT}_{50}\right)$ for EPNs against nymphs and adults was calculated from daily mortality data. The median lethal concentration $\left(\mathrm{LC}_{50}\right)$ of EPFs against adults was $\log _{10}$-transformed and calculated from the data obtained on the fourth day post-inoculation (dpi). $\mathrm{LT}_{50}$ and $\mathrm{LC}_{50}$ results with their fiducial confidence limits were obtained by $\mathrm{R}$ statistical package "ecotox" (Hlina 2020) based on the probit analysis (Finney 1971; Wheeler et al. 2006; Robertson et al. 2007). In the screening (EPFs) and greenhouse trials (EPNs and EPFs), mortality data of nymphs and adults were tested for normality and equality of variance with the Shapiro-Wilk test followed by Levene's test. Greenhouse trials data were subjected to ANOVA followed by Tukey's honestly significant difference (HSD) post-hoc test for multiple comparisons. Graphical representations of the statistical analysis results were produced using $\mathrm{R}$ statistical package "ggplot2" (Wickham et al. 2020). All the analyses were done using $\mathrm{R}$ (version 3.6.2) ( $\mathrm{R}$ Core Team 2019). 


\section{Results}

Biocontrol efficacy of entomopathogenic nematodes against $H$. obsoletus nymphs and adults

In the bioassay, $S$. carpocapsae was the most effective with a $\mathrm{LT}_{50}$ value of 3.24 and 3.69 days postinoculation (dpi) for $H$. obsoletus nymphs and adults, respectively (Fig. 1a, b). S. feltiae was the second most effective with a $\mathrm{LT}_{50}$ of 3.49 and 4.05 dpi for nymphs and adults, respectively (Fig. 1c, d). The mixture of $H$. bacteriophora and $S$. feltiae showed $\mathrm{LT}_{50}$ of 3.65 and $4.61 \mathrm{dpi}$ for nymphs and adults, respectively (Fig. 1e, f). H. bacteriophora (Hf) was the least effective with a $\mathrm{LT}_{50}$ of 4.34 and 5.06 dpi for nymphs for adults (Fig. 1g, h) (Supplementary Table S1). In the greenhouse trials, results of ANOVA [nymphs $\left(F_{4,10}=82.55 ; \quad p<0.001\right) ;$ adults $\left(F_{4,10}=87.96\right.$; $p<0.001)$ ], followed by Tukey's HSD test, revealed that the average mortality rate of $H$. obsoletus nymphs and adults treated with the different EPNs were significantly higher than the non-treated control. Among EPNs, S. carpocapsae showed the highest efficacy against $H$. obsoletus nymphs (average mortality rate $86.67 \%$ ) and adults (81.67\%), while $H$. bacteriophora the lowest ( $56.67 \%$ against nymphs; $55.00 \%$ against adults) (Fig. 2a, b; Supplementary Table S2).

Biocontrol efficacy of entomopathogenic fungi against $H$. obsoletus adults

In the initial screening, results of ANOVA $\left(F_{9,20}=20.39 ; \quad p<0.001\right)$, followed by Tukey's HSD test, revealed that the average mortality rate of $H$. obsoletus adults were significantly higher than the non-treated control in all EPFs treatments, except $B$. bassiana strain 1124 and M. anisopliae 1428 (Fig. 2c). In the bioassay, the seven effective EPFs were employed to define their proper concentration leading to $50 \%$ of mortality of $H$. obsoletus adults. I. fumosorosea strains 1497 and 1499 were found to be the most virulent against $H$. obsoletus adults with a $\mathrm{LC}_{50}$ ( $\log _{10}$ concentration) of 6.07 and 6.46 conidia $\mathrm{ml}^{-1}$, respectively. M. anisopliae strains 1429 and 1430 showed $\mathrm{LC}_{50}$ of 8.21 and 8.51 conidia ml $\mathrm{ml}^{-1}$, respectively. B. bassiana strains 1125 and 1126 were the least virulent with a $\mathrm{LC}_{50}$ of 8.89 and 9.23 conidia (a) Sc

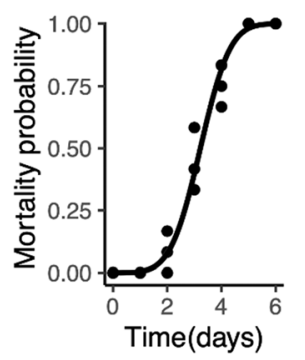

(e) $\mathrm{Hb}+\mathrm{Sf}$

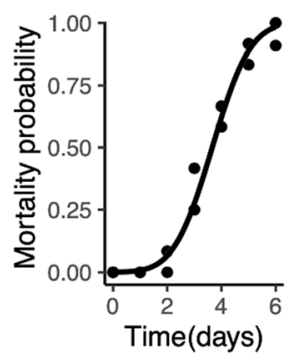

(b) Sc

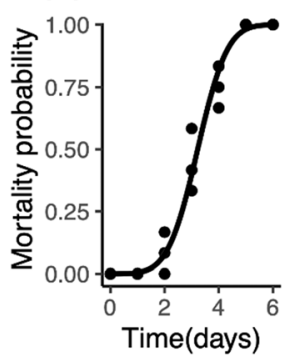

(f) $\mathrm{Hb}+\mathrm{Sf}$

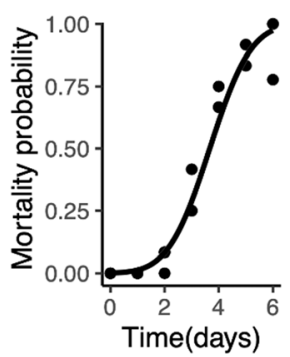

Fig. 1 Time-to-death curve of different EPNs against nymphs and adults of $H$. obsoletus. Black dots represent the observations. Black curves were computed within R statistical package "ecotox" using a glm smoothing method based on a binomial distribution with a probit link function. S. carpocapsae (Sc)

(c) $\mathrm{Sf}$

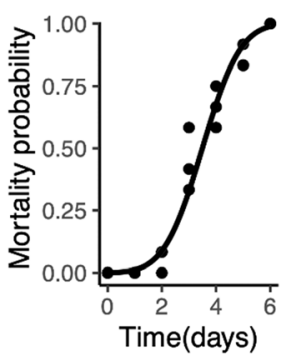

(g) $\mathrm{Hb}$

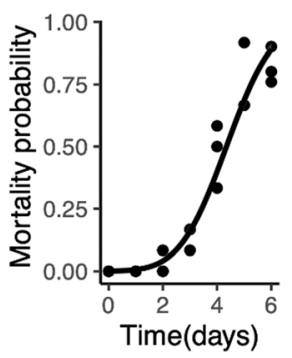

(d) $\mathrm{Sf}$

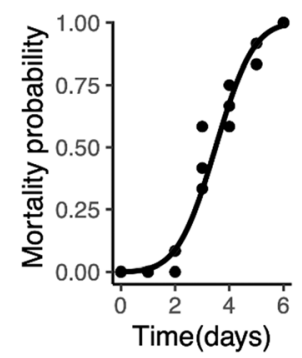

(h) $\mathrm{Hb}$

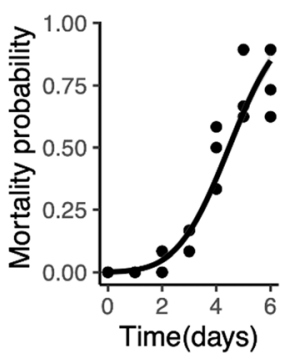

against $H$. obsoletus nymphs (a) and adults (b); S. feltiae (Sf) against nymphs (c) and adults (d); H. bacteriophora + S. feltiae $(\mathrm{Hb}+\mathrm{Sf})$ against nymphs $(\mathbf{e})$ and adults $(\mathbf{f}) ;$ H. bacteriophora $(\mathrm{Hb})$ against nymphs $(\mathbf{g})$ and adults $(\mathbf{h})$ 
(a)

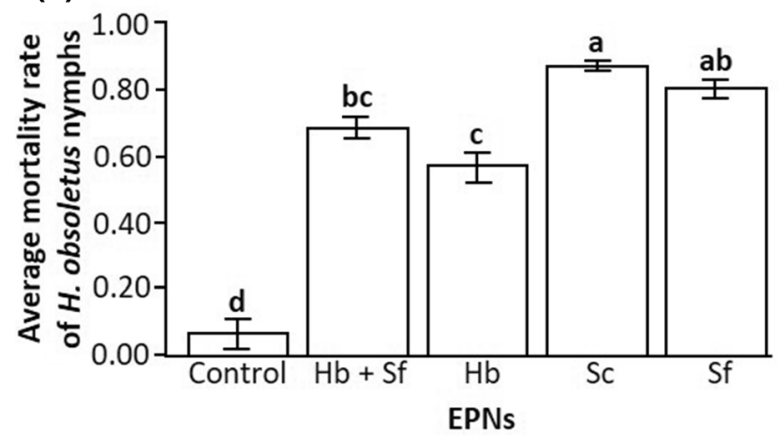

(c)

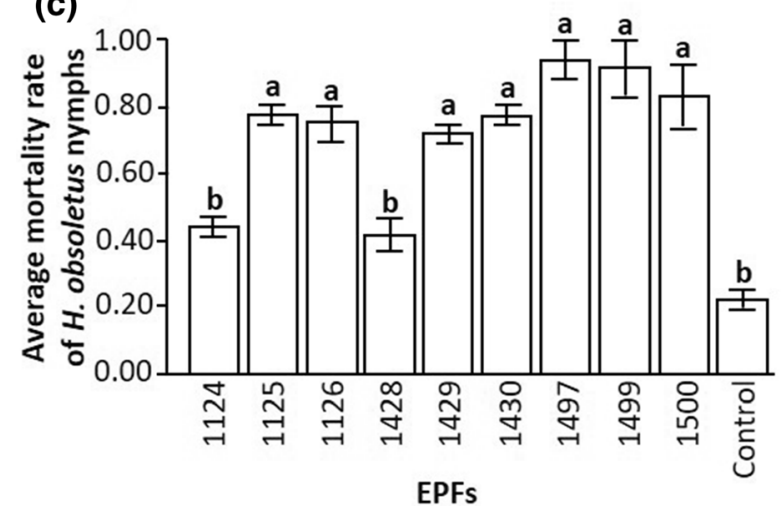

Fig. 2 Average ( $\pm \mathrm{SE}$ ) mortality rate of Hyalesthes obsoletus nymphs and adults treated with EPNs and EPFs. EPNs greenhouse trials against $H$. obsoletus nymphs (a) and adults (b); EPFs initial screening test against $H$. obsoletus adults (c); EPFs greenhouse trials against $H$. obsoletus adults (d). On each bar: letters (a-d) indicate significant differences $(p<0.05)$. Acronyms in (a) and (b): $\mathrm{Hb}+\mathrm{Sf}(H$. bacteriophora $+S$.

$\mathrm{ml}^{-1}$, respectively (Fig. 3; Supplementary Table S3). In the greenhouse trials, results of ANOVA $\left(F_{9,20}=23.87, \quad p<0.001\right)$, followed by Tukey's HSD test, revealed that the average mortality rate of $H$. obsoletus adults treated with the different EPFs were significantly higher than the non-treated control. Among EPFs, I. fumosorosea strain 1497 showed the highest efficacy against $H$. obsoletus adults (average mortality rate $91.1 \%$ ). This percentage was not significantly different in comparison to that obtained by I. fumosorosea strain 1499 (84.45\%), M. anisopliae strain $1111(75.56 \%)$, and L. muscarium strain 2222 $(80.00 \%)$. On the contrary, it was significantly different in comparison to that obtained by $M$. anisopliae strains 1429 (68.89\%) and 1430 (66.67\%), and $B$. bassiana strains 1125 (68.89\%). B. bassiana strain (b)

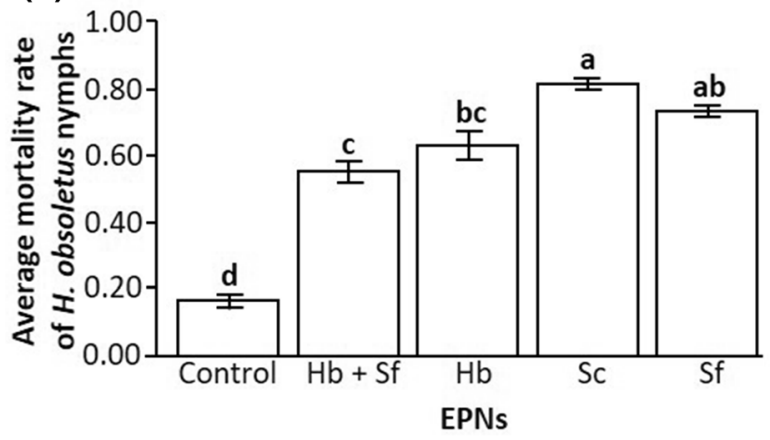

(d)

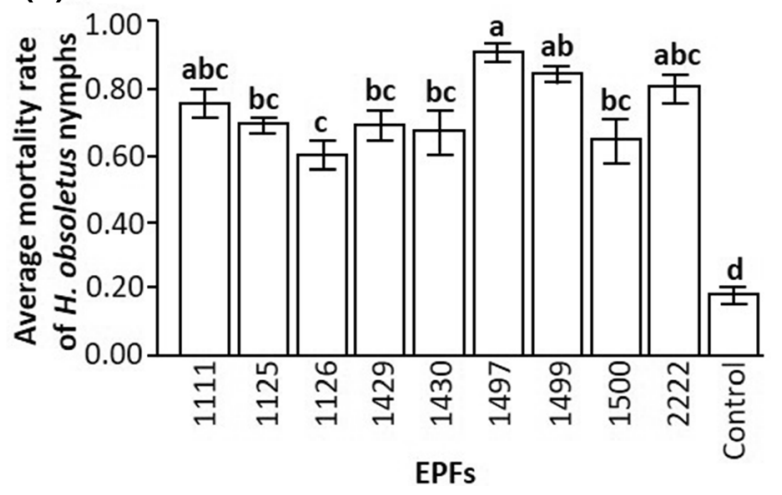

feltiae); Hb (H. bacteriophora); Sc (S. carpocapsae); Sf ( $S$. feltiae). Acronyms in (c) and (d): 1124, 1125, 1126 (B. bassiana strains JKI-BI-1124, JKI-BI-1125, JKI-BI-1126); 1428, 1429, 1430 (M. anisopliae strains JKI-BI-1428, JKI-BI-1429, JKI-BI1430); 1497, 1499, 1500 (I. fumosorosea strains JKI-BI-1497, JKI-BI-1499, JKI-BI-1500); 1111 (M. anisopliae strain 1111); 2222 (L. muscarium strain 2222)

1126 showed the lowest efficacy (60.00\%) (Fig. 2d; Supplementary Table S4).

\section{Discussion}

Due to the complex life cycle of Hyalesthes obsoletus, most strategies to control its populations in the vineyard agro-ecosystem are not effective or can impact the environment (Maixner and Mori 2013). In the last years, biocontrol has been proposed and frequently utilized as sustainable strategy to control plant pathogen insect vectors (Kumar 2016; AbdelRazek et al. 2017; Abd El-Ghany et al. 2018). Entomopathogenic nematodes (EPNs) and fungi (EPFs) have been largely employed as effective 
(a) 1125

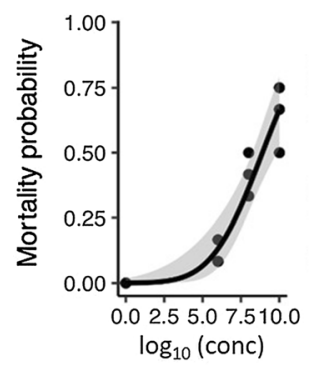

(e) 1497

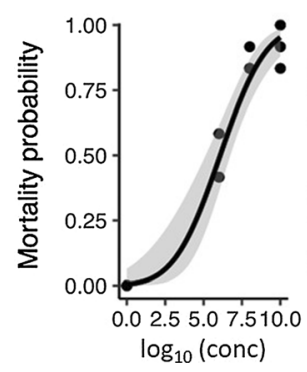

(b) 1126

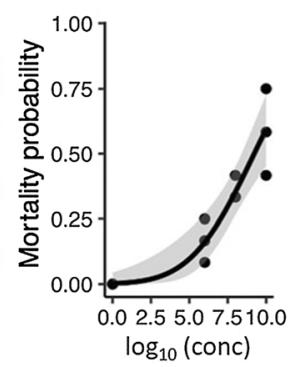

(f) 1499

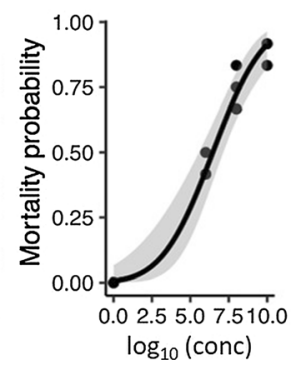

Fig. 3 Dose-response curve of EPFs against $H$. obsoletus adults. Black dots represent the observations. Black curves were computed within R statistical package "ecotox" using a glm smoothing method based on a binomial distribution with a probit link function. Shaded grey areas represent the $95 \%$ confidence

biocontrol agents against insects with a cryptic life cycle, including phytoplasma vectors (Grewal et al. 2005; Lacey and Georgis 2012; Guerrero and Pardey 2019), making this approach promising also for the main vector of 'Candidatus Phytoplasma solani' to grapevine, H. obsoletus.

The results obtained in this study demonstrated that all the examined EPNs are able to kill $H$. obsoletus nymphs and adults and that the EPFs, except Beauveria bassiana strain 1124 and Metharizium anisoploae strain 1428, are able to control the adults in both laboratory bioassays and greenhouse trials, exhibiting a range of effectiveness related to their virulence against the target insect. In all conducted trials, Steinernema carpocapsae and Isaria fumosorosea were found to be the most effective biocontrol agents of H. obsoletus among the examined EPNs and EPFs, respectively.

Concerning Steinernema spp., our findings are in agreement with Le Vieux and Malan (2013) showing that, in laboratory bioassay performed against the vine mealybug Planococcus ficus, the EPN Steinernema yirgalemense moved $15 \mathrm{~cm}$ vertically downward, and

(c) 1429

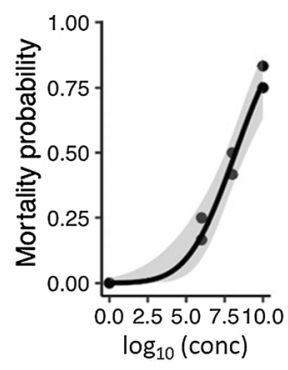

(d) 1430

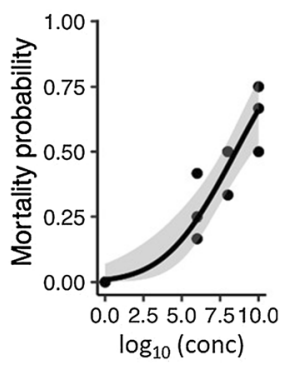

(g) 1500

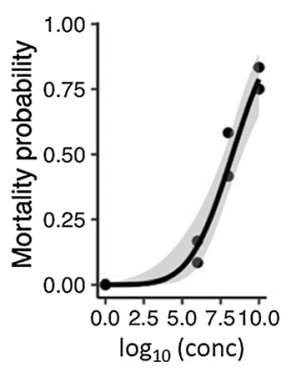

intervals. B. bassiana strains JKI-BI-1125 (1125) (a), JKI-BI1126 (1126) (b); M. anisopliae strains JKI-BI-1429 (1429) (c), JKI-BI-1430 (1430) (d); I. fumosorosea strains JKI-BI-1497 (1497) (e), JKI-BI-1499 (1499) (f), JKI-BI-1500 (1500) (g)

infected its insect target inducing a mortality of $95 \%$. Another study demonstrated that the combination of $S$. yirgalemense with specific adjuvants increased its biocontrol activity against the vine mealy bug on grapevine leaves in both laboratory and semi-field conditions (Platt et al. 2019). Such evidence fortifies the possibility of applying Steinernema spp. in the open field against both subterranean forms and adults of H. obsoletus. Among tested EPNs, also Heterorhabditis bacteriophora showed a high efficacy in $H$. obsoletus biocontrol. Interestingly, this EPN was reported to be effective against the nymphs of Haplaxius crudus, the insect vector of 'Candidatus Phytoplasma palmae' associated with Palm Lethal Yellowing disease in Florida, USA (Guerrero and Pardey 2019), and of Aeneolamia spp., a putative vector of genetically distinct phytoplasmas (Pérez Miliàn et al. 2018). Moreover, H. bacteriophora strongly reduced the survival of the root-form of grapevine phylloxera (English-Loeb et al. 1999). This evidence highlighted that, in vineyard agroecosystems, treatments based on the application of $H$. bacteriophora could be effective against multiple 
insect pests. Based on all these evidences, it would be interesting to apply a combination of $S$. carpocapsae, found here as more effective against $H$. obsoletus nymphs and adults, and $H$. bacteriophora, reported in previous studies as the most effective EPN against phytoplasma insect vectors and grapevine insect pests with a cryptic life stage.

Concerning Isaria fumosorosea, found here as the most effective EPF against $H$. obsoletus, previous studies showed its biocontrol activity against various nymphal stages of the green leafhopper Empoasca decipiens Paoli under laboratory and greenhouse conditions (Tounou et al. 2003; Kodjo et al. 2011). Similar efficacy was found by treatments with $\mathrm{Me}$ tarhizium anisopliae (strain Ma43) and Beauveria bassiana (strain Bba113) (Tounou et al. 2003; Kodjo et al. 2011). For all these EPFs, percentage of mortality and $\mathrm{LC}_{50}$ values reported against $E$. decipiens were comparable to those observed in this study against $H$. obsoletus adults. Moreover, promising results obtained in the present study with two strains of $M$. anisopliae confirmed its entomopathogenic activity against $H$. obsoletus adults under laboratory conditions (Langer et al. 2005). Interestingly, Beauveria bassiana, two strains of which showed a great biocontrol activity against $H$. obsoletus adults in the present work, was found naturally infecting and causing visual symptoms on $H$. obsoletus adults in Georgia (Caucasus region) (Chkhaidze et al. 2017). Moreover, B. bassiana showed an efficacy in biocontrol of young stages and adults of Scaphoideus titanus Ball, the insect vector of flavescence dorée phytoplasma, in semi-field and field trials (Mori et al. 2014b). All these evidences underlined that $B$. bassiana can control both the insect vectors of phytoplasmas associated with the main grapevine yellows diseases. Thus, B. bassiana strains represent really promising EPFs for application in vineyards.

Effectiveness of EPNs and EPFs, as well as other living organisms used as biocontrol agents, depends on a range of climatic and environmental parameters allowing their liveliness and entomopathogenic activity. In particular, it is crucial that the target insect stage is present when climatic parameters are optimal for EPNs and/or EPFs (Lacey and Georgis 2012; Wang and Wang 2017). In the case of $H$. obsoletus, it is known that the duration of the cryptic (subterranean) phase of its life cycle, involving the nymph stages, is dependent on the degree day units that can be estimated based on forecasting models measuring the accumulated heat units (Maixner and Mori 2013). Such models allow understanding of the life cycle of the insect as well as narrowing the spraying window of products for plant protection, including EPNs and EPFs. In particular, the spraying window should prioritize two important aspects: (1) the ecological competency of EPNs as well as EPFs; (2) the proper timing for application against the different stages and instars of $H$. obsoletus. In Europe and the Mediterranean area, considering the life cycle of $H$. obsoletus and the environmental conditions suitable for EPNs and EPFs utilized in the present study, it should be recommended to apply EPNs and EPFs on $\mathrm{H}$. obsoletus host plants in the open field from mid-September to October and/or in early spring to optimize the activity of each biocontrol agent and avoid resistance in the insect target populations. Moreover, given their ability to colonize the soil after their inoculation (Meyling and Eilenberg 2006; Denno et al. 2008), EPNs and EPFs could reduce the $H$. obsoletus population density for a long time. According to our result EPFs could be applied also with foliar application from end of May till end of June against newly hatched adults before grapevine infestation. Optimized application of entomopathogenic nematodes (on the soil) and fungi (on the plants) can increase the control of $H$. obsoletus nymphs and adults, respectively.

In conclusion, the majority of EPNs and EPFs utilized in the present study showed a considerable biocontrol activity against $H$. obsoletus nymphs and adults in laboratory bioassays and greenhouse trials. The ecological competency of both EPNs and EPFs, the conditions that can impede or enhance their performance, the barriers that can block infection from taking place on the target host, and the possible actions on non-target species should be carefully investigated for a better understanding of their potential performance under field conditions.

Acknowledgements The authors thank Prof Itamar Glazer of ARO, Volcani Center, ISRAEL for his suggestions and text revision.

Authors' contribution Abdelhameed Moussa: Conceptualization, data curation, formal analysis, investigation, methodology, validation, writing - original draft. Michael Maixner: conceptualization, methodology, resources, supervision, writing - review and editing. Dietrich Stephan: 
methodology, resources, writing - review and editing. Giacomo Santoiemma: data curation, formal analysis, validation. Alessandro Passera: data curation, formal analysis, validation. Nicola Mori: conceptualization, project administration, resources, supervision, Writing - review and editing. Fabio Quaglino: conceptualization, project administration, supervision, writing - review and editing.

Funding Open Access funding provided by Università degli Studi di Verona, Italy.

\section{Compliance with ethical standards}

Conflict of interest The authors declare that there are no conflicts of interest associated with this publication.

Ethical approval This research did not involve any studies with human participants or animals (vertebrates) performed by any of the authors.

Open Access This article is licensed under a Creative Commons Attribution 4.0 International License, which permits use, sharing, adaptation, distribution and reproduction in any medium or format, as long as you give appropriate credit to the original author(s) and the source, provide a link to the Creative Commons licence, and indicate if changes were made. The images or other third party material in this article are included in the article's Creative Commons licence, unless indicated otherwise in a credit line to the material. If material is not included in the article's Creative Commons licence and your intended use is not permitted by statutory regulation or exceeds the permitted use, you will need to obtain permission directly from the copyright holder. To view a copy of this licence, visit http://creativecommons.org/licenses/by/4.0/.

\section{References}

Abd El-Ghany NM, Abdel-Razek AS, Djelouah K, Moussa A (2018) Efficacy of bio-rational insecticides against Tuta absoluta (Meyrick) (Lepidoptera: Gelechiidae) on tomatoes. Biosci Res 15:28-40

Abdel-Razek AS, Abd El-Ghany NM, Djelouah K, Moussa A (2017) An evaluation of some eco-friendly biopesticides against Bemisia tabaci on two greenhouse tomato varieties in Egypt. J Plant Prot Res 57:9-17

Alma A, Tedeschi R, Lessio F, Picciau L, Gonella E, Ferracini C (2015) Insect vectors of plant pathogenic mollicutes in the Euro-Mediterranean region. Phytopath Moll 5:53-73

Angelini E, Constable F, Duduk B, Fiore N, Quaglino F, Bertaccini A (2018) Grapevine phytoplasmas. In: Rao GP, Bertaccini A, Fiore N, Liefting LW (eds) Characterisation and epidemiology of phytoplasma-associated diseases. Phytoplasmas: plant pathogenic bacteria-I. Springer, Singapore, pp 123-152

Bertin S, Picciau L, Acs Z, Alma A, Bosco D (2010) Molecular differentiation of four Reptalus species (Hemiptera: Cixiidae). Bull Entomol Res 100:551-558
Bianco PA, Romanazzi G, Mori N, Myrie W, Bertaccini A (2019) Integrated management of phytoplasma diseases. In: Bertaccini A, Weintraub GP, Rao GP, Mori N (eds) Transmission and management of phytoplasma-associated diseases. Phytoplasmas: plant pathogenic bacteria-II. Springer, Singapore, pp 208-237

Bressan A, Turata R, Maixner M, Spiazzi S, Boudon-Padieu E, Girolami V (2007) Vector activity of Hyalesthes obsoletus living on nettles and transmitting a stolbur phytoplasma to grapevines: a case study. Ann Appl Biol 150:331-339

Cargnus E, Pavan F, Mori N, Martini M (2012) Identification and phenology of Hyalesthes obsoletus (Hemiptera: Cixiidae) nymphal instars. Bull Entomol Res 102:504-514

Chkhaidze N, Burjanadze M, Lobghanidze M, Koridze K (2017) First report of entomopathogenic fungi on the insect vector Hyalesthes obsoletus Signoret (Hemiptera: Cixiidae) in Georgia. IOBC/WPRS Bull 129:43-46

Cvrković T, Jović J, Mitrović M, Krstić O, Toševski I (2014) Experimental and molecular evidence of Reptalus panzeri as a natural vector of bois noir. Plant Pathol 63:42-53

Denno RF, Gruner DS, Kaplan I (2008) Potential for entomopathogenic nematodes in biological control: a metaanalytical synthesis and insights from trophic cascade theory. J Nematol 40:61-72

English-Loeb G, Villani M, Martinson T, Forsline A, Consolie N (1999) Use of entomopathogenic nematodes for control of grape phylloxera (Homoptera: Phylloxeridae): a laboratory evaluation. Environ Entomol 28:890-894

Finney DJ (1971) Probit analysis. Cambridge University Press, Cambridge

Glazer I, Lewis EE (2000) Bioassays for entomopathogenic nematodes. In: Navon A, Ascher K (eds) Bioassays of entomopathogenic microbes and nematodes. CABI, pp 229-247

Green CD (1964) The effect of crowding upon the fecundity of Folsomia candida (William) var. Distincta (Bagnall)(Collembola). Entomol Exp Appl 7:62-70

Grewal P, Lewis E, Gaugler R, Campbell J (1994) Host finding behaviour as a predictor of foraging strategy in entomopathogenic nematodes. Parasitology 108:207-215

Grewal PS, Ehlers RU, Shapiro-Ilan DI (2005) Nematodes as biocontrol agents. CABI Publishing, Wallingford

Guerrero MR, Pardey AEB (2019) Selection of entomopathogenic nematodes to control nymphs of Haplaxius crudus (Van Duzee) (Hemiptera: Cixiidae). Am J Entomol 3:24-29

Hlina BL (2020) Ecotox: Analysis of ecotoxicology. R package version 1.4.2

Kaya HK, Burlando T, Thurston GS (1993) Two entomopathogenic nematode species with different search strategies for insect suppression. Environ Entomol 22:859-864

Kaya HK, Stock SP (1997) Chapter VI - techniques in insect nematology. In: Lacey LA (ed) Manual of techniques in insect pathology. Academic, London, pp 281-324

Kirchmair M, Huber L, Porten M, Rainer J, Strasser H (2004) Metarhizium anisopliae, a potential agent for the control of grape phylloxera. Biol Control 49:295-303

Kodjo T, Hans-Michael P, Komi A, Katharina R, Gilbert Z, Christian B (2011) A laboratory assessment of the potential of selected entomopathogenic fungi to control the green 
leafhopper Empoasca decipiens Paoli (Homoptera: Cicadellidae). J Appl Biosci 47:3195-3204

Kosovac A, Jakovljević M, Krstić O, Cvrković T, Mitrović M, Toševski I, Jović J (2019) Role of plant-specialized Hyalesthes obsoletus associated with Convolvulus arvensis and Crepis foetida in the transmission of 'Candidatus Phytoplasma solani'-inflicted bois noir disease of grapevine in Serbia. Eur J Plant Pathol 153:183-195

Kumar OB (2016) Biocontrol of insect pests. In: Omkar (ed) Ecofriendly pest management for food security. Elsevier, San Diego, pp 25-61

Lacey LA (1997) Manual of techniques in insect pathology. Academic, London

Lacey LA, Georgis R (2012) Entomopathogenic nematodes for control of insect pests above and below ground with comments on commercial production. J Nematol 44:218-225

Langer M, Maixner M (2004) Molecular characterisation of grapevine yellows associated phytoplasmas of the stolburgroup based on RFLP-analysis of non-ribosomal DNA. Vitis 43:191-199

Langer M, Maixner M, Kirchmair M, Huber L (2005) Efficacy of Metarhizium anisopliae against Hyalesthes obsoletus (Auchenorryhncha: Cixiidae). Vitis 44:99-100

Le Vieux PD, Malan AP (2013) The potential use of entomopathogenic nematodes to control Planococcus ficus (Signoret)(Hemiptera: Pseudococcidae). South Afric J Enol Viticul 34:296-306

Maixner M (1994) Transmission of German grapevine yellows (Vergilbungskrankheit) by the planthopper Hyalesthes obsoletus (Auchenorrhyncha: Cixiidae). Vitis 33:103-104

Maixner M, Johannesen J (2014) Optimized monitoring of host populations of the bois noir vector, Hyalesthes obsoletus, based on flight phenology observations. IOBC/WPRS Bull 105:151-157

Maixner M, Mori N (2013) Management of bois noir through vector control. Phytopath Moll 3:4-46

Meyling NV, Eilenberg J (2006) Occurrence and distribution of soil borne entomopathogenic fungi within a single organic agroecosystem. Agric Ecosyst Environ 113:336-341

Mori N, Mitrović J, Smiljković M, Duduk N, Paltrinieri S, Bertaccini A, Duduk B (2013) Hyalesthes obsoletus in Serbia and its role in the epidemiology of corn reddening. Bull Insectol 66:245-250

Mori N, Pavan F, Maixner M (2014a) Control of Hyalesthes obsoletus nymphs based on chemical weeding and insecticides applied on Urtica dioica. Vitis 53:103-109

Mori N, Tonello D, Posenato G, Pozzebon A, Duso C (2014b) Efficacy of biopesticides against Scaphoideus titanus ball in different experimental conditions. IOBC/WPRS Bull 105:45-48

Moussa A, Mori N, Faccincani M, Pavan F, Bianco PA, Quaglino F (2019) Vitex agnus-castus cannot be used as trap plant for the vector Hyalesthes obsoletus to prevent infections by 'Candidatus Phytoplasma solani' in northern Italian vineyards: experimental evidence. Ann Appl Biol 175:302-312

Pérez Miliàn JR, Pérez Pérez Y, Álvarez JF, Ruano Rossil JM (2018) Biological control of sugarcane froghopper, Aeneolamia spp., by the nematode Heterorhabditis bacteriophora and entomopathogenic fungi Metarhizium anisopliae and Beauveria bassiana as economically sustainable option. CEIBA 55:21-27

Platt T, Stokwe NF, Malan AP (2019) Foliar application of Steinernema yirgalemense to control Planococcus ficus: assessing adjuvants to improve efficacy. South Afr J Enol Viticul 40:1-7

Quaglino F, Sanna F, Moussa A, Faccincani M, Passera A, Casati P, Bianco PA, Mori N (2019) Identification and ecology of alternative insect vectors of 'Candidatus Phytoplasma solani' to grapevine. Sci Rep 9:19522

Quaglino F, Zhao Y, Casati P, Bulgari D, Bianco PA, Wei W, Davis RE (2013) 'Candidatus Phytoplasma solani', a novel taxon associated with stolbur-and bois noir-related diseases of plants. Int J Syst Evol Microbiol 63:2879-2894

R Core Team (2019) R: A language and environment for statistical computing. R Foundation for Statistical Computing, Vienna, Austria (https://www.r-project.org/)

Robertson JL, Savin NE, Russell RM, Preisler HK (2007) Bioassays with arthropods. CRC Press

Sharon R, Tomer M, Sokolsky T, Sofer-Arad C, Zahavi T (2015) Trap plants reduces grapevine yellows disease incidence in commercial vineyards. Phytopath Moll 5:S107-S108

Stöckmann M, Biedermann R, Nickel H, Niedringhaus R (2013) The nymphs of the planthoppers and leafhoppers of Germany. WABV Fründ

Tounou AK, Agboka K, Poehling HM (2003) Evaluation of the entomopathogenic fungi Metarhizium anisopliae and Paecilomyces fumosoroseus (Deuteromycotina: Hyphomycetes) for control of the green leafhopper Empoasca decipiens (Homoptera: Cicadellidae) and potential side effects on the egg parasitoid Anagrus atomus (Hymenoptera: Mymaridae). Biocontrol Sci Tech 13:715-728

Wang C, Wang S (2017) Insect pathogenic fungi: genomics, molecular interactions, and genetic improvements. Annu Rev Entomol 62:73-90

Wheeler MW, Park RM, Bailey AJ (2006) Comparing median lethal concentration values using confidence interval overlap or ratio tests. Environ Toxic Chem 25:1441-1444

Wickham H, Chang W, Henry L, Pedersen TL, Takahashi K, Wilke C, Woo K, Yutani H, Dunnington D (2020) ggplot2: Create elegant data visualisations using the grammar of graphics. R package version 3.3.2

Abdelhameed Moussa is a doctoral candidate at Department of Agricultural and Environmental Sciences, University of Milan, Italy. His $\mathrm{PhD}$ project focuses on developing integrated sustainable strategies for the control of grapevine bois noir disease.

Michael Maixner is deputy head of the Institute for Plant Protection in Fruit Crops and Viticulture, Julius Kühn-Institut, Siebeldingen, Germany. His research activity focuses on etiology, epidemiology, and control of phytoplasma diseases and other vector transmissible diseases of grapevine.

Dietrich Stephan is head of the Microbiology and Bioengineering laboratory and leads the working group Entomopathogenic fungi at Institute for Biological Control, Julius Kühn-Institut, Darmstadt, Germany. His research focuses on 
production, formulation, and application of micro-organisms for plant protection.

Giacomo Santoiemma has a post-doc position at Department of Agronomy, Food, Natural resources, Animals and Environment, University of Padova, Italy. His research focuses on spatial ecology and environmental data analysis of insect pests and vectors.

Alessandro Passera has a post-doc position at Department of Agricultural and Environmental Sciences, University of Milan, Italy. His research interests are beneficial endophytic bacteria, biocontrol agents, and microbiota in relation to plant health.
Nicola Mori is professor of general and applied entomology at Department of Biotechnology, University of Verona, Italy. His research focuses on biology and ecology of insect pests and phytoplasma vectors, and their control through sustainable strategies.

Fabio Quaglino is professor of plant pathology at Department of Agricultural and Environmental Sciences, University of Milan, Italy. His research focuses on taxonomy and ecology of phytoplasmas, and epidemiology and control of the associated diseases. 